\title{
The possibilities of application of programmed instruction in the sixth grade of the second cycle of education in accordance with standards
}

\author{
Dragana Milošević $A^{*}$, Ljubica Ivanović Bibić ${ }^{B}$, Smiljana Đukičin ${ }^{B}$, \\ Anđelija Ivkov Džigurski ${ }^{B}$, Branko Ristanović ${ }^{B}$ \\ Received: March 23, 2016 | Revised: May 29, 2016 | Accepted: June 6, 2016
}

DOI: $10.18421 / G P 20.02-01$

\begin{abstract}
The subject of the work is to determine the possibilities of application of programmed instruction in the teaching of geography in the case of the sixth grade students of the second cycle of education. On the basis of an experimental research the rationale for the use of this form of acquiring knowledge during the classes of processing new material is presented. The primary task of the research functioning is to determine the degree of benefits of programmed instruction when adopting new geographical teaching contents and what is the extent of applicability of this method of learning with the aim of improving teaching. The second task of the work is the application of the experiment in two classes, the control (C) and experimental (E), based on which it is established which vision of learning, programmed or conventional, achieves the best results in processing geographical contents in primary school.
\end{abstract}

Keywords: programmed instruction, geography, education, educational standards, primary school, Serbia

\section{Introduction}

The application of programmed instruction has its roots in ancient Greece. Programmed instruction was a special process of teaching which begins with ancient philosopher Socrates. Socrates presented the segments of knowledge to his students in the form of short wholes. The students were required to adopt previous contents so that the teaching process went on continuously. By mastering the steps of teaching contents a possibility for incentive in further progress was opened (Romelić, Ivanović Bibić, 2015). Principles of this kind of teaching were later applied in the work of teachers individually or with a pair of pupils. The teacher's mission is in the short presentation of the topic as well as in asking questions and tasks, and after that the level of communication, depending on the answers,would be adjusted to students' abilities. Scientifically justified and established approach to programmed instruction appears as a result of rapid development of science and accumulation of scientific facts. In great number of cases it was insisted on remembering large numeral and factual material. Those problems should have been overcome by well- organized programmed instruction in the sense that pupils ruled only the key terms, and later on used those in specific teaching situations.

Prodanović and Ničković (1974, 372) determined programmed instruction in the following way: "programmed instruction is the way of learning where teaching material is in a special way logically structured and given to students in smaller, previously prepared parts, which they adopt individually, gradually, going step by

\footnotetext{
A Elementary school Svetozar Marković, Kosovskih junaka 10, 34220 Lapovo, Serbia

B University of Novi Sad, Faculty of Sciences, Department of Geography, Tourism and Hotel Management, Trg Dositeja Obradovića 3, 21000 Novi Sad, Serbia

* Corresponding author: Dragana Milošević, e-mail: drmilosevic@live.com
} 
step in their own rhythm and they check the degree of the adoption of contents by constant and current feedback information". Bakovljev (1998) defined programmed instruction as a teaching system where students individually process programs in which both the content and the way of learning are specified in details, including notification procedure about achieved results.

Programmed instruction became known thanks to the work of an American psychologist B. F. Skinner, a professor at Harvard University, who elaborated linear programming in 1954 (Tomić, Osmić, 2006). By criticizing Skinner's program, Crowder (1959) created his own branched program. Special machines for teaching were constructed and they were based on Skinner's and Krowder's theoretical assumptions.

The basic characteristics of programmed instruction that Skinner stated in his theory of teaching are: keeping only things that are important in the teaching material and dismiss everything that is irrelevant, division of material into smaller parts (sequences) which can only be completely adopted, overcoming the parts on the principle from easier to more difficult, practical use of adopted knowledge and constant feedback information during the teaching process as well as corroboration through that information.

Skinner expended the base of earlier researches and came to important conclusions in the field of teaching theory. Skinner's starting point is reduced to the known problem: stimulus-reaction-corroboration. According to him, teaching consists of shaping human behavior. By constant corroboration, on one hand, it comes to desired forms of behavior, and on the other hand, it comes to gradual weakening and removing of those forms of behavior that are unwanted. Later on he developed linear programming "step by step" (Tomić, Osmić, 2006).

The basis of Skinner's teaching is based on the fact that every step in learning should be as small as possible. By that the number of repeating former knowledge can be increased to maximum, while the possible source of mistakes is kept to a minimum (Milojević, 1999). The essence of his linear program is in that that every student should be familiar with the content in the form of short presentations, and then look for the concrete answer or solution of the problem and every student must have the feedback information about the accuracy of his/her answer.

On the other hand, Crowder considered that small steps are not stimulant enough, that they fragment the material too much. That is why he starts from the bigger steps, more difficult tasks and multiple choice tasks. If a student gives an incorrect answer, he is given the necessary explanation and is offered the second time choice. When he comes up with the correct answer, new information is given to him (Milojević,
1999). In other words, in Crowder's model a student has a possibility to choose one answer from more alternative answers that are offered to him, that is to give an answer that he considers correct. If he chose the wrong answer, the student would examine the whole process of former work and discover where he had made a mistake. According to that, branched program directs a student to take additional steps and explains him where he has made mistakes. In this way individual thinking of students and the ability to detect things are more intensively developed. Very important contribution of branched program is the fact that it creates conditions for individualization of teaching process (Milojević, 1999). Unlike Skinner, who neglected the way in which a student is oriented on giving the correct answer, Crowder put that as one of important factors of realization of the program and accomplishment of the student's process. Crowder made communication in the process of teaching more dynamic and enabled bigger individualization and development of one's own opinion.

The period between the 6o's of the last century brought up the revolution of ideas about the possibilities of use of programmed instruction. Special attention should be paid to the works of: Crowder (1959), Crowder (1960), Dixon (1964), Edwards (1966), Goldbeck and Campbel (1962), Green (1962), Hartley (1966).

B. Bloom (1981) gave his contribution for experimental and practical use of programmed instruction in schools by his taxonomy of educational goals. Moscow Phsychology School, which developed on the theory of Leo Vygotski (according to Tomić, Osmić, 2006), also gave its contribution.

\section{Basic terms in programmed instruction}

In programmed instruction basicterms are: program, theme, sequence, article (step, portion, dose), algorithm. The program in programmed instruction is significantly different from the clasical teaching program in which the contents that should be learned are generally indicated. It is up to a teacher to decide about the volume and length of processing. In programmed instruction the term program has more cybernetic conotation. That program specifically exposes all important facts and terms that students need to learn. Teaching material is displayed in small parts, connected to each other and easy for adopting, which are learned one after the other. Learning of the parts of the lower degree of complexity is a condition for understanding more complex parts. For that reason contents cannot be "skipped".

The theme is a substential, logically structured whole from the teaching material. The sequence is logically structured part of the theme (substential whole). 
The article (step, portion, dose) is the smallest unit in programmed instruction. Algorithm is the pattern, i.e. a precise guidance with determined sequence of operations which need to be done in order to solve the problem. The use of algorithm in teaching provides a possibility to simplify the process of education, and for the students it facilitates solving problems of the same type because they have a routed way in advance. Members of Moscow Psychology School worked most on algorithmization of the teaching process, both theoretically and practically, and there the algorithm is the integral part of programmed instruction. The teaching material that is made as algorithm is the one that fulfills the request for massiveness, i.e. they prepare the algorithm which can be wider used. When it comes to individual examples for which the algorithm is not suitable, then a precise instruction, which is close to algorithm, is prepared (Vilotijević, 200o).

\section{Types of programs for programmed instruction}

There are three types of programs that are distinguished: linear, branched and combined (Vilotijević, 2000). Besides the linear and branched there is also improved linear program, in other words its variants modified linear, linear program with extra lines, linear program with test articles and conversational-chain program. Linear program was created by Skinner starting from his principles of programmed instruction "step by step". The articles in that program are arranged rectilinear. All students solve the same problems in a set order and in their own rhythm, depending on the foreknowledge and cognitive abilities. Students solve the problems alone, without choosing answers, because they are not offered to them. In that way they activate their thinking. Students can check if they solved the problems correctly because the answers are given in the program (Živković, Jovanović, 2010).

The advantage of linear programs is that they enable every student to work at his own pace. The disadvantage is that they do not give the possibility for seeking additional information which are not included in the problem, but which some students need in order to get to solutions. Linear program individualizes only the rhythm of mastering the material, but it does not accept differences in students' abilities.

Branched program removes some weaknesses of rectilinear programming. In it articles are set rectilinear, but then they go sideways, and those sideway articles (problems) lean on the closest rectilinear article. In this program, with each problem there are more answers, and the student chooses the one he thinks is correct.

The good side of the branched program is in the fact that it enables the student who knows some of the problems to "skip" them, and for the one who does not know, the article directs to search for additional information in the "sideway" article. Those students who have more knowledge move rectilinear, and those who have less knowledge and abilities move on the broken line. Branched program enables not only individualized pace of learning but also enables differentiation of teaching contents and procedures. The disadvantage of branched program, in regard to linear is less thoughtful activity of students who do not solve problems but choose solutions from the given ones (Vilotijević, 2000; Vilotijević, Vilotijević, 2008).

Combined program, as the combination of linear and branched program, has the purpose to join the advantages, and avoid weaknesses of both programs. The elements of branched program are brought in in the linear one so that the contents would differentiate to some point (as well as methods of learning) (Bakovljev, 1972; 1979; 1982).

The use of programmed instruction in practice shows that linear system of program is most often used in cases when students need to remember factual material; branched program is mostly used when material does not contain bigger quantity of references or terms, but the extent of information is big; combined programs are used in learning different teaching contents (Mužić, 1974; Trnavac, Đorđević, 1998).

\section{Creating a program and the requirements that have to be met by the program}

The main prerequisite for the success of programmed instruction is the quality of the program itself. That operational document is made by a teacher or a group of teachers - experts in the corresponding subject, then a pedagogue, a psychologist, an ICT teacher (Živković, Jovanović, 2010). The creation of programmed instructional material funds is particularly important as a base for a successful expansion of programmed instruction. Prior to wide application in practice, these materials should be verified through the trial realization. These materials, which are proved to be good, could be widely used, published and procured for school libraries (Vilotijević, 20oo). There are eight phases in creating the curriculum for programmed instruction:

1. The partition of the general aims of teaching into the concrete ones (operationalization) so that their achievement in the teaching process can be measured through the knowledge, skills and habits;

2. The preparation of thematic curriculum that will include all the stages in the realization of learning objectives;

3. Un-programmed exposure of the total teaching material that should be provided for programmed 
instruction. This is the basis of a future program, as the thematic plan does not express links between certain parts of the material that are strong enough. We can also use students' books as the unprogrammed material and, in that case, the material is selected and summarized;

4. The partition of individual themes into small articles "portions" that must be linked in a logical sequence. Each article must be precisely worked out so it could be implemented through specific practical actions;

5. Singled out and analyzed articles, "steps", are entered into a matrix that is the basis of a future program. The formation of the matrix is the most complex stage in programming;

6. Elaboration of the operational implementation of each article, the "steps". As a part of this stage the feedback is formulated, the control of each student's work is worked out, the tests are formulated;

7. Elaboration of the opening and final presentations of each group of topics, elaboration of methodical instructions for the teacher in order to use the program in the teaching process;

8. Checking of the program in teaching with a limited number of students. The objective of this check is to remove mistakes and weaknesses through a trial practical work that would contribute to the improvement of the program (Vilotijević, 2000).

The material that has a clear logical structure can be programmed. In the material structure that will be programmed we have to extract the essential elements that are interrelated in terms of the content and logically and that are connected casually and consequently. These are the smallest units of knowledge, or programmed articles that are popularly known as "meals" or "portions" of knowledge (Branković, Ilić, 2003). Basic requirements that have to be met by the programmed instruction program are: user-friendliness, distinctness and resultativeness.

User-friendliness is achieved by exposing all the essential concepts and facts of the content provided for the school subject, by partition of the teaching material into articles that are logically connected and easy to adopt, and are overcome gradually (in logical order).

Distinctness is achieved by algorithmic structure of the program which allows the achievement of the stated goal of learning by carrying out planned operations, that is the gradual achievement of more complex thinking activities.

Resultativeness is achieved by the accurate assessment of the cognitive abilities of students and the organization of the teaching process adapted to each student (Vilotijević, 2000).

\section{Methodology and phases of the pedagogical experiment}

Experimental part of the research was conducted during the school year 2013/14. The research included two classes of the sixth grade of Elementary school "Svetozar Marković" in Lapovo. In the experimental group (E group), the methods and techniques of programmed instruction were used during the lessons (Geographical features of the Western, Northern and Eastern Europe with the exemplary countries), while the lessons with the control group (C group) included the traditional methods and techniques. Both groups of students had an initial test, a final test and a retest at the same time. Both groups of students had the same criteria when testing. In pedagogical research the instruments of the testing were the same and the questionsincluded all three levels of achievement: basic, intermediate and advanced.The obvious advantage of programmed instruction and its practical application is in its concreteness. A student gets the information about contents of the teaching unit on teaching worksheets. The teaching worksheets incurred as a result of a partial replacement of the student's book. Information given in the teaching worksheets are very precise, we do not go towards generalization. Programmed geography student's books in our teaching practice do not exist. Teaching worksheets are the primary source of information and guidance to students.

Teaching worksheets contain one or more piece of information and thus they enable students to adopt teaching content independently and gradually, at their own pace until the final adoption of the teaching material. Information is a part of the material which contains sequences of basic, intermediate or advanced level of knowledge defined by the verbs of Bloom's taxonomy.

After reading each piece of information, a student gets tasks. After solving the tasks, the student is given feedback on his performance. If the student does the given task incorrectly, he receives additional information from the teacher in order to detect his mistake, but also he is obligated to return to the previously read information in order to re-read it and adopt it. If the student's answer is correct, he immediately does a new task. When the student answers all the questions related to a certain piece of information correctly, he can read the next information, i.e. a new part of the material and so on until the end, until the full adoption of the content of the teaching unit. By obtaining the feedback on his performance, the student can assess his achievement realistically at any moment and pay more attention to elimination of deficiencies in his own advancement. The student can skip some pieces of information or articles at his own insistence, 
but, in order to move on to the following information, he must do all the tasks which were contained in the information he has skipped. This situation is possible if the student has a high level of awareness, knowledge and achievements in Geography. At the end of each class, students do a final test. The test contains all the questions whose answering unifies all the individual pieces of information into a whole.

The research included the following stages which were scheduled by the authors (Krulj, Stojanović, Krulj-Drašković, 2007):

- Initial assessment of the students of $\mathrm{E}$ and $\mathrm{C}$ group,

- Realization of pedagogical experiment in both groups,

- Final testing of the students and

- Re-testing of the students.

Knowledge of curriculum, as well as its understanding and application, were followed at three levels: basic, intermediate and advanced.

One of the key features of the experimental pedagogical research is that it examines the effectiveness of educational work. The aim of this study was to determine the efficacy of programmed instruction of geography in the sixth grade of the second cycle of education in accordance with educational standards compared to traditional teaching. In this study, an experimental method was applied.

Parallel groups were made up of two sixth grade classes of the second cycle of education in elementary school "Svetozar Marković" in Lapovo. In order to accomplish the experimental research the groups were equal according to the criteria of overall achievement at the end of the previous school year. Due to the fact that each grade of the second educational cycle has three classes, the main factors for the selection and establishment of control and experimental groups were students' grade- point average and students' achievement in Geography. In the control group the teaching was in accordance with the traditional model of realization of the content of lessons.The control group was used for control or establishing the value of the procedure to be applied in the second group. In the experimental group, students adopted the same content of teaching units with the application of programmed instruction. Differences between the groups were realized through the analysis of the results in the control and experimental groups after the completion of pedagogical research.

SPSS 21.0 software package was used for statistical analysis of data obtained in tests: initial, final and retest (Kožuh, Maksimović, 2011; 2013). To determine the relationship between two variables we used t-test (t) with the threshold of significance $p=0.05$ as well as a correlation coefficient (r). The level of the independ- ent variable relative to dependent one was obtained by calculating the etecorrelation $(\eta)$.

The null research hypothesis $\left(\mathrm{H}_{\mathrm{o}}\right)$ reads:

Application of programmed instruction in the realization of the content of teaching units, in all experimental groups will not have a statistically significant impact on increasing their overall efficiency in geography teaching.

The alternative research hypothesis $\left(\mathrm{H}_{\mathrm{a}}\right)$ reads:

Application of programmed instruction in the realization of the content of teaching units, in all experimental groups will have a statistically significant impact on increasing their overall efficiency in geography teaching.

In order to concretize and map out the null hypothesis, we started from the following research sub-hypothesis $\left(\mathrm{H}_{1-3}\right)$ :

$\mathrm{H}_{1}$ : E group students will achieve significantly better results on the final test at each level: basic, intermediate and advanced, as well as on the test as a whole compared to C group students, which is a result of greater efficiency of the application of programmed instruction in geography teaching in relation to traditional one.

$\mathrm{H}_{2}$ : E group students will achieve significantly better results on the retest at each level: basic, intermediate and advanced, as well as on the test as a whole compared to $\mathrm{C}$ group students, which is a result of greater efficiency of the application of programmed instruction in geography teaching in relation to traditional one.

$\mathrm{H}_{3}$ : E group students will achieve significantly better results on the retest at each cognitive domain, as well as on the test as a whole compared to $C$ group students, which is a result of greater quality and durability of their knowledge gained by the application of programmed instruction in geography teaching in relation to traditional one.

\section{Initial test}

With a view to equalizing the experimental and control group, students' previous knowledge was measured by the initial test.

Contents checked by the initial test were related to teaching topics that students learned in the previous grade. The maximum number of points that could be earned on the initial test was 9, while the maximum level of requirement was 18 and included the questions from the three levels of knowledge: basic, intermediate and advanced:

1. Basic level contained two different types of questions: "Circle the letter of the correct answer" or closed questions "Fill in the sentences with the words that are missing so that the statements are correct" or open questions. 
2. Intermediate level had three different types of questions. Closed questions, open questions and "Edit the information". According to Bloom's taxonomy, intermediate level corresponds to the cognitive domain of understanding concepts.

3. Advanced level contained questions "Edit the information" which, according to Blum (1981), also includes cognitive domain of analysis and reasoning.

Students were scored according to the following scale of points: 0-2 points mark insufficient (1), 3 points mark sufficient (2), 4-5 points mark good (3), 6-7 points mark very good (4) and 8-9 points mark excellent (5).

\section{Final test and retest}

Final test and retest were related to the content of teaching units that were presented during the realization of pedagogical experiment. The final test was given after finishing eight teaching units for the purpose of analysis of the acquisition of teaching contents and evaluation of effects of applied learning models in groups $\mathrm{E}$ and $\mathrm{C}$ after the research.

Retest was given 60 days after the final test in order to determine the durability of the acquired knowledge from the realized teaching content in groups $\mathrm{E}$ and C.

As in the case of the initial test, the maximum number of points that could be earned on the final test and the retest was 9 and contained questions from the three levels of knowledge: basic, intermediate and advanced. Stages of testing were the same as on the initial test.

The ultimate goal is to increase the educational effects in geography teaching. It is difficult to expect the same results in the control group where teaching units will be presented by using traditional teaching methods and forms of work.

\section{The results of pedagogical experiment and discussion}

Initial assessment of the students of groups $\mathrm{E}$ and $\mathrm{C}$ was done at the beginning of the school year 2013/2014. The initial test was aimed at equalization of the students of groups $\mathrm{E}$ and C. T-test of independent samples showed no statistically significant difference between the mean values of groups $\mathrm{E}$ and $\mathrm{C}$, not at individual levels, nor on the test as a whole. The results show that the students of experimental and control group were initially equalized by the level of knowledge in Geography, which means that they had similar level of previous knowledge related to Geography. The results obtained enabled the continuation of the research or study of the influence of experimental factor and the performance of the relevant conclusions after research had been done. After the eight teaching units were completed in the experimental and control group, a final test was done. In the experimental group teaching content was presented by using the programmed instruction, while in the control group the same content was presented by using traditional method of teaching.

In order to test whether the students of group $\mathrm{E}$ would achieve better results on the final test at each level and on the test as a whole in comparison with the students of group C, we awarded points. The final test, as well as the re-test, had 18 questions. Each question had two requests, so that the total number of points was 9 . The student who answered correctly could get 0.5 points. The student who had 1 and 2 points got the

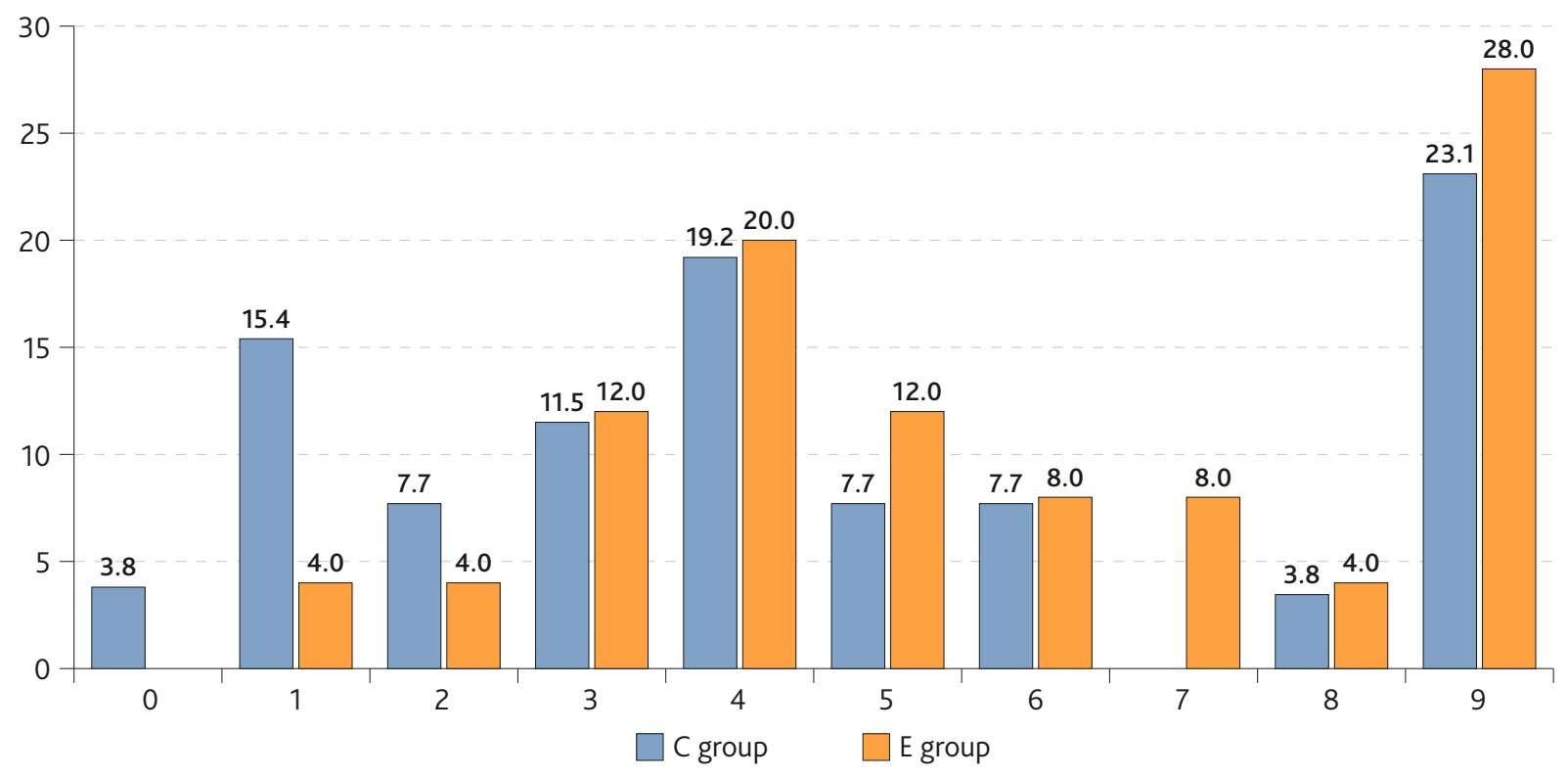

Figure 1. Points earned by the sixth grade students in groups $E$ and $C$, on the final test as a whole (in \%) 
mark insufficient (1), for 3 points the mark was sufficient (2), for 4-5 points the mark was good (3), for 6-7 points the mark was very good (4) and for 8-9 points the student got the mark excellent (5). Observed by the level criterion and student achievement standards, basic level had four requests, intermediate level eight and advanced level six.

On the final test in the sixth grade the greatest number of students in E (28.0\%) and C (23.1\%) group achieved 9 points. But when we have a look at the frequency of other points, the results show that more than half of the students in the experimental group $(60.0 \%)$ achieved five or more points, while more than half of the students in the control group (57.6\%) achieved fewer than five points. When we have a look at the mean value of the actual number of points on the final test as a whole with the sixth grade students, the results show that the mean is greater in group $\mathrm{E}$ (5.8), in comparison with the group C (4.6).

The sixth grade students in group $\mathrm{E}$ were given the highest mark and the mark good in the same percentage $(32.0 \%)$, while students in group $\mathrm{C}$ had the same number $(23.9 \%)$ of the marks insufficient, good and excellent. When we have a look at the mean value of the actual number of points on the final test, the results show that the students in group $\mathrm{E}$ achieved significantly better results compared to students in group $\mathrm{C}$ at all levels and on the test as a whole. The arithmetic mean of the number of points earned on the final test as a whole in group E was 5.7 , and in group C 4.3 points. The difference between the arithmetic mean of these two groups was 1.3 in favor of group E, and t-test of independent samples showed that this difference is statistically significant $t(195)=-3.55, p=0.000$. The difference between the mean value of the groups is moderate (eta squared $=0.1$ ).

T-test of independent samples showed a statistically significant difference between mean values of $\mathrm{E}$ and $\mathrm{C}$ group at each level $(\mathrm{p}<0.01)$, and the differenc-

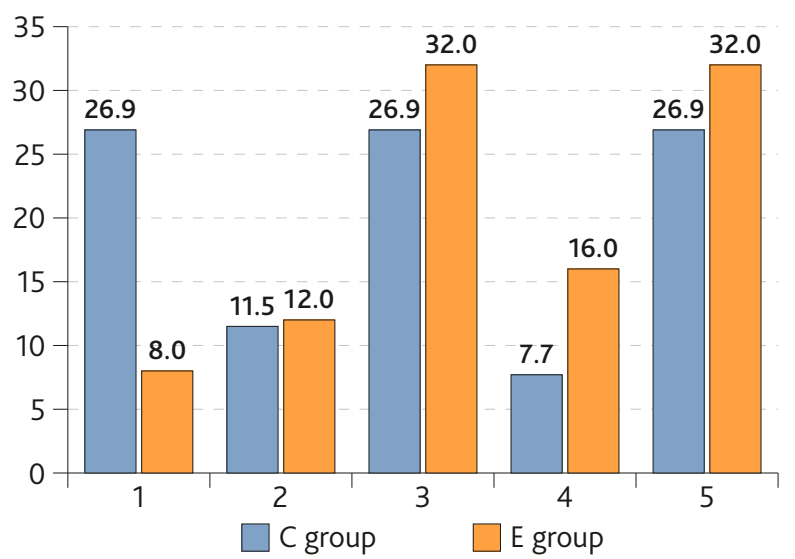

Figure 2. Marks of the sixth grade students in $\mathrm{E}$ and $\mathrm{C}$ group, on the final test as a whole (in \%)

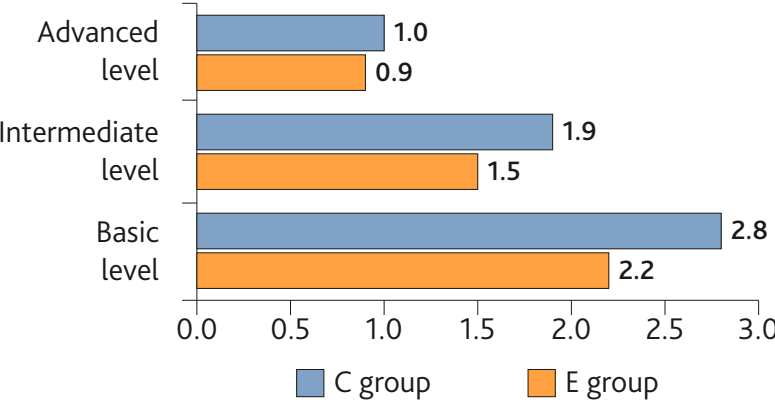

Figure 3. The mean value of points earned by the sixth grade students in groups $\mathrm{E}$ and $\mathrm{C}$ on the final test at all levels

es between groups are small (eta squared in the range of 0.03 to o.o). The arithmetic mean of the number of points earned on the final test at each level is higher in group $\mathrm{E}$ compared to the mean of group $\mathrm{C}$, and the results show that the biggest difference between the mean values is at the advanced level- 0.5 , while the least one is at the basic level - 0.4 in favor of group E.

The results show that the students in the experimental group achieved significantly better results on the final test at each level (basic, intermediate and advanced), as well as on the test as a whole compared to students in the control group. The results achieved by the students in groups $\mathrm{E}$ and $\mathrm{C}$ indicate greater efficiency of the application of programmed instruction in Geography teaching compared to traditional teaching which is still the most commonly used in elementary schools in Serbia (Ivanović Bibić, et al., 2015; Đukičin, et al., 2014; Leščešen, et al., 2013).

The arithmetic mean of the number of points earned on the retest as a whole in group E was 5.48, and in group $\mathrm{C} 3.54$ points. The difference between the arithmetic mean of these two groups was 1.94 in favor of group E, and t-test of independent samples showed that this difference was statistically significant $t(198)=-4.79, p=0.000$. The difference between the groups was moderate (eta squared $=0.1$ ).

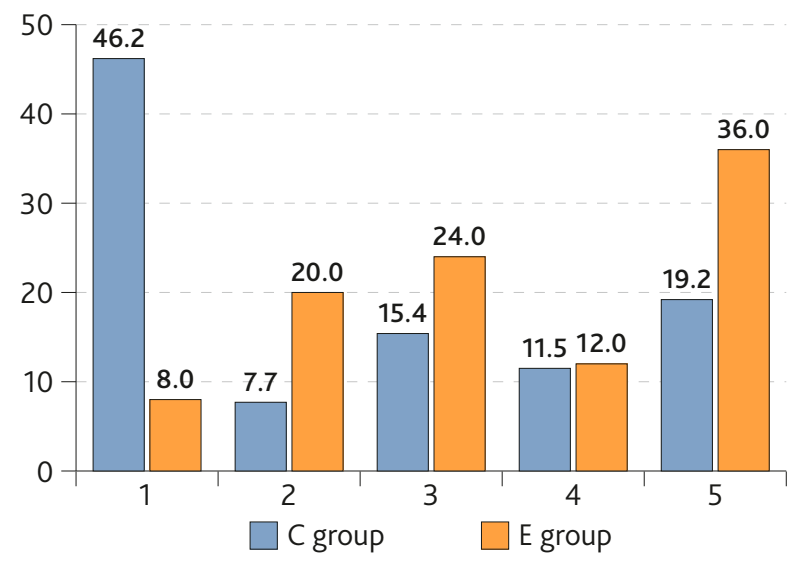

Figure 4. Marks of the sixth grade students, groups $\mathrm{E}$ and $\mathrm{C}$, on the re-test as a whole (in \%) 


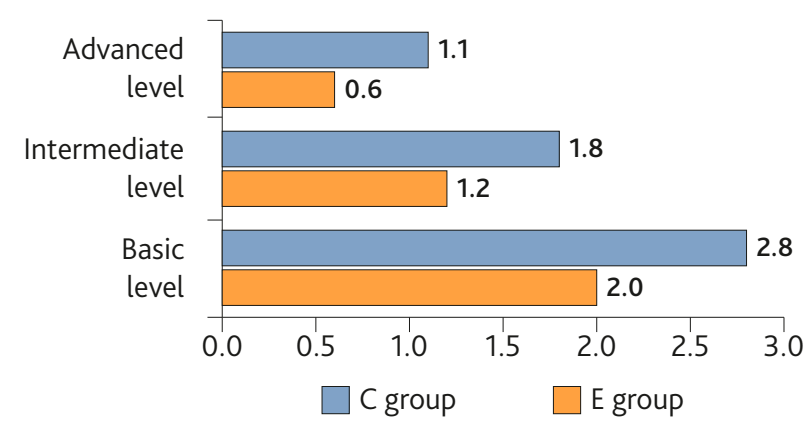

Figure 5. The mean values of points earned by the sixth grade students, groups $\mathrm{E}$ and $\mathrm{C}$ on the retest, at all levels

T-test of independent samples showed a statistically significant difference between the mean values of $\mathrm{E}$ and $\mathrm{C}$ group at each level $(\mathrm{p}<0.01)$, and the difference between the mean values of the groups is moderate at the basic (eta squared $=0.1$ ) and advanced level (eta squared $=0.1$ ), while the intermediate level difference is small (eta squared $=0.0$ ). At each of the levels, the arithmetic mean of the actual number of points on the retest is greater in group $\mathrm{E}$ compared to the mean of group C.

Results show that the mean value of the actual number of points on the retest at each level is higher in group E, compared to the students in group $\mathrm{C}$, suggesting that the students of the experimental group achieved better results compared to the control group of students at all levels. In the sixth grade, the difference is the greatest at the basic level (0.88), and the lowest at the advanced level (0.50), in favor of group E.

\section{Conclusion}

In order to get independent students in teaching process, programmed instruction occupies a special place. It enables students to broaden and enrich their experiences, and to progress at the pace that respects their personal preferences and intellectual capabilities. Although this is the form of teaching in which the students' activity is greater than in traditional classes, it also requires additional engagement of teachers, as well as new roles. For the success of programmed instruction, the partnership of students and teachers is important, as well as functional communication between all participants in the program. The teacher provides support for students' activities during their work, as well as help if necessary. The (teacher) manages the project in a way that leaves enough space for self-organization of the students. Also, the teacher is more active in providing conditions and materials for the project, as well as in solving problems that go beyond the students' abilities.
Modernization of teaching Geography represents the continuous efforts by both theory and practice. In accordance with the requirements of society and the needs that are changing in the era of permanent education, the individual is certainly expected more in the process of cognition. Simple reproduction suppresses the production of knowledge. One of the main tasks of teaching Geography is that students acquire knowledge permanently in order to apply it in new teaching and life situations, and to minimize the process of forgetting in every manner possible. In the new situation, where classes are monitored in accordance with their capabilities, well aware of the fact that he is able to develop, a student self-fulfills the tasks and uses different sources of knowledge. Application of programmed instruction removes the subjectivity of teachers, which increases the extent of the additional motivation of students. Advantages of programmed instruction are beyond its drawbacks. There is very limited experience of the application of programmed instruction in elementary schools and even in practice. The aim of this study was to determine the efficacy of programmed instruction in relation to the common or everyday teaching models and methods. On the basis of pedagogical experiment with the rotation of groups $\mathrm{C}$ and $\mathrm{E}$, which was conducted on the sample of the sixth grade students, the following conclusions may be drawn:

Statistical analysis showed that the students of the experimental group did better on the final test which confirmed the starting hypothesis.

The results of the final tests show that greater efficiency is present in the classes with the implementation of programmed instruction. When we look at the mean value of points on the final test at each level earned by the classes, the results show that students of group E at the basic, intermediate and advanced level achieved better results compared to students in group $\mathrm{C}$ which confirmed the sub-hypothesis.

Statistical analysis showed that the students of the experimental group did better on the final test after the rotation. After the rotation, the results show that the largest number of students of group E (30.8\%) achieved three points, while $26.9 \%$ of the students of the mentioned group achieved a maximum of nine points.

Programmed teaching has a modest presence in our educational practice. In order to improve on that, it is necessary to change the organization of work in schools in terms of additional equipment and teaching aids. Additional motivation of subject and class teachers is not a negligible factor. Since programmed instruction is often defined by some methodologists as teaching for future, it can meet the demands of technocracy that recruit young individuals to learn continuously throughout their lives. 


\section{References}

Bakovljev, M. 1972. Theoretical basis of programmed instruction. Duga, Belgrade. (in Serbian)

Bakovljev, M. 1979. Programmed instruction of punctuation. Institut za pedagoška istraživanja i Prosveta, Belgrade. (in Serbian)

Bakovljev, M. 1982. Thought activation of students in the classroom. Prosveta, Belgrade. (in Serbian)

Bakovljev, M. 1998. Didactics. Naučna knjiga, Belgrade. (in Serbian)

Blum, B. 1981. Taxonomy and classification of educational goals. Republic Institute for the Improvement of Education, Belgrade. (in Serbian)

Branković, D., Ilić, M. 2003. Basics of pedagogy. Comesgrafika, Banja Luka.

Crowder, N. A. 1959. Automatic Tutoring by Means of Intrinsic Programming. In: Galanter, E. (ed.) Automatic Teaching: The State of the Art, New York: Wiley, 109-116 pp.

Crowder, N. A. 1960. Automatic Tutoring by Intrinsic Programming. In: Lumsdaine, A. A. and Glaser, R. (eds.) Teaching Machines and Programmed Learning, Washington: D.A.V.I., 286-298 pp.

Dixon, J. R. 1964. A Programmed Introduction to Probability. Wiley, New York.

Đukičin, S., Ivanović Bibić, Lj., Lukić, T., Dubovina, Z. 2014. Analysis of the Utilization of Supplementary Illustrations - An Example of the Selected Teaching Units from the Fifth Grade Geography Textbook. Geographica Panonnica 18, 4, 89-95.

Edwards, K. F. 1966. Programmed Learning in the United Kingdom. Praha, Pedagogicky Ustav JAK ČSAV, 40-51.

Goldbeck, R. A., Campbell, V. N. 1962. The effects of Response Mode and Response Difficulty on Programmed Learning. Journal of Eductional Psychology $53,110-118$

Green, E. J. 1962. The Learning Process and Programmed Instruction. New York, Holt, Rinehart and Winston, $228 \mathrm{pp}$.

Hartley, J. 1966. Social Factors in Programmed Instruction - A Review. Programmed Learning 3, 1, 3-13.

Ivanović Bibić, Lj., Đukičin, S., Lukić, T., Miljković, Đ., Milanković, J., Babić Kekez, S., Ivkov Džigurski, A., Dubovina, Z. 2015. Achieving Competencies with
Grammar School Students through Utilization of Selected Didactical Principles - Case Study of Geographic features of Europe. Geographica Panonnica 19, 4, 153-161.

Kožuh, B., Maksimović, J. 2011. Descriptive statistics in pedagogical research. Faculty of Philosophy, Niš. (in Serbian)

Kožuh, B., Maksimović, J. 2013. The use of PSPP programin pedagogical research. Faculty of Philosophy, Niš. (in Serbian)

Krulj, R., Stojanović, S., Krulj-Drašković, J. 2007. Introduction to the methodology of pedagogical research with statistics. Teacher Education Faculty, Center for Scientific Research,Vranje. (in Serbian)

Leščešen, I., Ivanović Bibić, Lj., Dragin, A., Balent, D. 2013. Problems of teaching organisation in combined (split) classes in rural areas of the Republic of Serbia.Geographica Panonnica 17, 2, 54-59.

Milojević, S. 1999. Programmed instruction-interactive learning. Ministry of Education of The Republika Srpska and UNICEF Office in Banja Luka, Banja Luka.

Mužić, V. 1974. Programmed instruction. Školska knjiga, Zagreb. (in Croatian)

Prodanović, T., Ničković, R. 1974. Didactics: for the students of the fifth and the sixth year of the teacher training college. Institute for textbooks and teaching aids, Belgrade. (in Serbian)

Romelić, J., Ivanović Bibić, Lj. 2015. Methodology of Teaching Geography. University of Novi Sad, Faculty of Sciences, Department of Geography, Tourism and Hotel Management, Novi Sad, 324 pp. (in Serbian)

Tomić, R., Osmić, I. 2006. Didactics. Denfas, Tuzla.

Trnavac, N., Đorđević, J. (1998). Pedagogy.Naučna knjiga, Belgrade. (in Serbian)

Vilotijević, M. 200o. Didactics: didactic and learning theories.Teacher Education Faculty, Belgrade. (in Serbian)

Vilotijević, M., Vilotijević, N. 2008. Innovation in teaching. Teacher Education Faculty in Vranje, Vranje. (in Serbian)

Živković, Lj., Jovanović, S. 2010. The theoretical framework of programmed instruction in geography teaching. Collection of works LVIII, Faculty of Geography, University of Belgrade, Belgrade. (in Serbian) 